Rhode Island College

Digital Commons @ RIC

\title{
$5-2018$
}

\section{Identification of Barriers to SBARB at the Bedside in an Acute Care Setting}

Elizabeth Bryand

Follow this and additional works at: https://digitalcommons.ric.edu/etd

Part of the Nursing Commons

\section{Recommended Citation}

Bryand, Elizabeth, "Identification of Barriers to SBARB at the Bedside in an Acute Care Setting" (2018). Master's Theses, Dissertations, Graduate Research and Major Papers Overview. 261.

https://digitalcommons.ric.edu/etd/261

This Major Paper is brought to you for free and open access by the Master's Theses, Dissertations, Graduate Research and Major Papers at Digital Commons @ RIC. It has been accepted for inclusion in Master's Theses, Dissertations, Graduate Research and Major Papers Overview by an authorized administrator of Digital Commons @ RIC. For more information, please contact digitalcommons@ric.edu. 



\section{IDENTIFICATION OF BARRIERS TO SBARP AT THE BEDSIDE IN AN ACUTE CARE SETTING}

\section{A Major Paper Presented}

by

Elizabeth Bryand

Approved:

Committee Chairperson

Committee Members

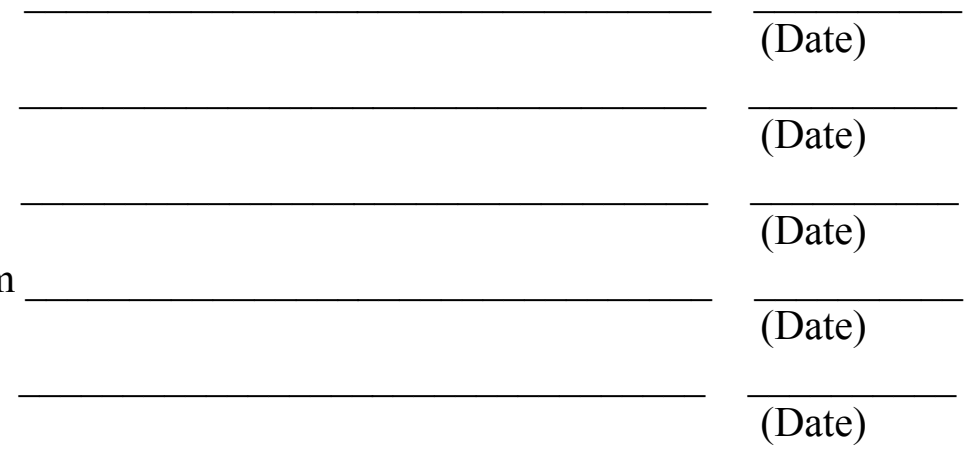

Director of Master's Program

Dean, School of Nursing 
IDENTIFICATION OF BARRIERS TO SBARP AT THE BEDSIDE

IN AN ACUTE CARE SETTING

by

Elizabeth Bryand

A Major Paper Submitted in Partial Fulfillment

of the Requirements for the Degree of

Master of Science in Nursing

in

The School of Nursing

Rhode Island College

2018 


\begin{abstract}
Nurse to nurse handoff that occurs at the end of each shift is a known area of potential safety risk due to poor communication and inadequate safety checks. The Joint Commission (TJC) reported that communication between healthcare providers or between patient and healthcare providers was the leading root cause of sentinel events. Research supports the benefits of a structure handoff at the bedside to patient safety and satisfaction. Despite these proven benefits, staff nurses have not consistently embraced the practice. The purpose of this study was to identify nurses' perceived barriers to performing SBARP (Situation, Background, Assessment, Recommendation and Patient) at the bedside in an acute care setting. Rogers Diffusion of Innovation Theory was used to guide the development and implementation of this project. A mixed qualitative and quantitative survey was utilized to assess the nurses' perceived barriers to performing SBARP at the patient's bedside. The survey was distributed to nurses employed on two medical-surgical floors at Newport Hospital. Responses $(\mathrm{N}=19)$ showed that although staff nurses perceived that bedside handoff positively impacted patient satisfaction and patient safety, they did not routinely practice bedside handoff. Nurses cited lack of comfort with the practice, patient privacy, perception of time, and communication of sensitive information as barriers to performing bedside handoff. Sustaining practice change over time in an organization can be challenging. Leadership support and enforcement of bedside handoff in addition to targeted education to reduce perceived barriers to the practice may help to increase the practice of bedside handoff.
\end{abstract}




\section{Acknowledgements}

It is hard to believe that graduate school is ending, but one thing I know for certain is that I would not have been successful without the support of my teachers, family, friends and co-workers. I would like to thank Cindy Padula, $\mathrm{PhD}, \mathrm{RN}$, Patricia Calvert MSN, APRN, GCNS-BS and Kathy Bergeron MS, RN CNS-BC CEN, my first, second and third readers for their endless effort, patients and support that me through this project. Thank you to my husband, Dan, and sister, Emma, whose encouragement, care and help provided me with the time and perseverance to complete school assignments and classes. Lastly, thank you to my co-workers whose teamwork allowed me to adjust my schedule to meet school requirements. I am truly grateful for the chance to continue my education and career in nursing. 


\section{Table of Contents}

Background/Statement of the Problem ................................................................

Literature Review......................................................... 3

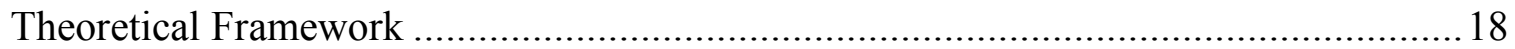

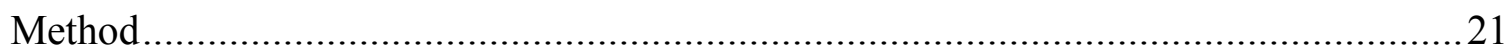

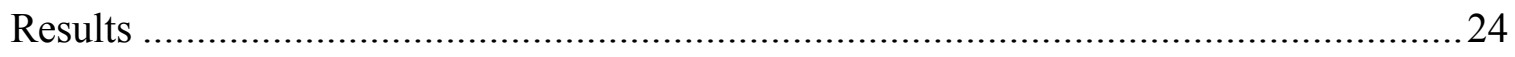

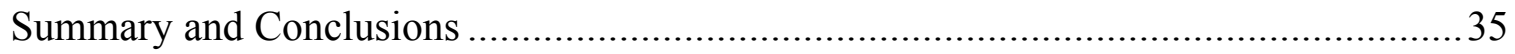

Recommendations and Implications for Advanced Nursing Practice..........................39

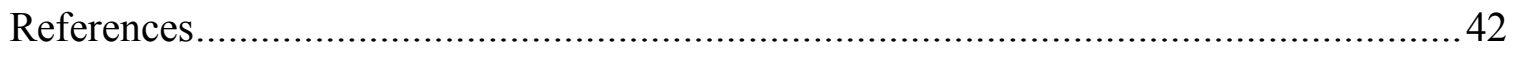

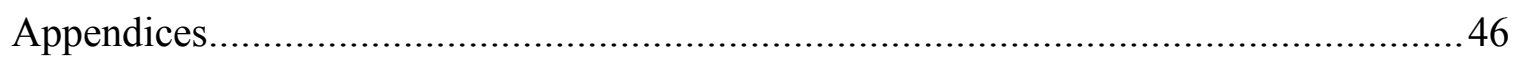


Identification of Barriers to SBARP at the Bedside in an Acute Care Setting Background/Statement of the Problem

In healthcare, communication in a clear standardized manner increases patient safety by reducing communication errors (The Joint Commission [TJC], 2007). A known area of potential safety risk due to poor communication and inadequate safety checks is nurse to nurse handoff that occurs at the end of each shift. The Joint Commission reported that communication between healthcare providers or between patient and healthcare providers was the leading root cause of sentinel events.

Kaiser Permanente first introduced the Situation, Background, Assessment and Recommendation (SBAR) reporting structure in 2002 as a tool for concise, clear and focused communication between nurses and physicians and quickly became a tool to use for nurse to nurse communication. The organization derived SBAR communication from the navy's high reliability procedures. The structure of SBAR assists healthcare providers to avoid digressing and helps to ensure staff communicate essential components of the plan of care (Kaiser Permanente, 2007). Using a structured report format will facilitate the transfer of accurate information during handoff, and assist in the prevention of missed information during handoff (Cornell, Gervis, Yates, \& Vardaman, 2014). Including the patient in the handoff and plan of care discussions increases patient satisfaction (Tobiano, Chaboyer, \& McMurray, 2012).

As healthcare has shifted to a patient centered focus, SBAR has transitioned to SBARP: Situation, Background, Assessment, Recommendations and Patient to include the patient in communication (Kaufman, 2008). The setting of nurse to nurse handoff has also changed from a desk or conference room to the bedside. However, anecdotal 
information and observation shows that nurses are resistant to performing handoffs at the bedside, despite proven patient satisfaction and safety benefits (Anderson \& Mangino, 2006).

Lifespan has been using the SBAR reporting structure as far back as 2006. Throughout these years, various tools have been added to support the use of the SBAR reporting (Dufault et al., 2010). In 2010, Lifespan introduced the concept of bedside reporting to include the patient in the handoff process. In 2015, the SBARP tool became embedded in Lifespan's electronic medical record. Despite these proven benefits of nurse handoff at the bedside, some staff have not embraced the practice (Dufault, 2017; Duquette et al., 2013). Further inquiry may help to determine factors that prevent staff nurses from performing bedside SBARP handoff.

The purpose of this study was to identify nurses' perceived barriers to performing SBARP at the bedside in an acute care setting. Next, the review of the literature will be presented. 


\section{Literature Review}

The Cumulative Index to Nursing and Allied Health Literature (CINAHL) and PubMed databases were used to perform a search of relevant literature. Key search terms used included communication, nurse to nurse communication, handoff, bedside handoff, beside nurse report, SBAR and SBARP at the bedside. The search included articles published from the year 2000 until July of 2017.

\section{Communication's Influence on Patient Safety}

In 1999, the Institute of Medicine (IOM) published To Err is Human, edited by Kohn, Corrigan and Donaldson, which called for health care organizations to evaluate their practices and make healthcare safer. The report cited failure of communication as a commons source of error. To improve safety, the report recommended reducing reliance on memory and using standardized protocols and checklists. To continually improve the culture of safety, the IOM also recommended using regulatory agencies, such as TJC or Medicare and Medicaid, to evaluate a healthcare organizations' procedures, thereby holding the organization accountable to standardized expectations (Kohn, Corrigan, \& Donaldson, 2000).

In 2007, TJC reported that communication between healthcare providers or between patient and healthcare providers was the leading root cause of sentinel events (TJC). In 2016, TJC published the 2017 National Patient Safety Goals which still included goals to "improve staff communication" and to "identify patients correctly" (TJC). Patient handoff or transfer of care between two healthcare providers is a vulnerable time and the quality of patient handoff can impact patient safety (Taylor, 2015). 
Johnson, Carta, and Throndson (2015) performed a quality improvement project to examine how patient information was obtained and shared among nurses. The researchers interviewed 39 nurses from multiple units who gave verbal report either at the patients' bedside, away from the patient or used tape recorded reports. Interviewers took notes and then met to review the data. Four themes were identified, including poor documentation, no plan of care identified for the patient, variable communication patterns and consistency of patient assignments. Verbal report was not guided by a specific format, and staff noted that the quality of verbal report was usually related to the experience level of the RN providing the report. Staff preferred verbal report for the opportunity to ask questions and clarify information. The researchers noted that patient safety and quality care resulted from effective communication and poor communication can result in poor outcomes for patients. After interviewing the nurses, the researchers implemented a SBAR handoff template. They found use of the SBAR tool allowed nurses to capture the big picture and to create and follow a detailed plan of care.

Kear (2016) performed a systemic review to define patient handoff, the connection between handoffs and patient safety, and the best practices for handoffs in a nephrology practice setting. Kear used CINAHL, Pubmed, MEDLINE, Cochrane Library and ProQuest databases to search for full text articles published between 2010 and 2016 using the keywords "handoffs, patient handoff, nursing report, shift handoff, nursing handover, patient transitions, and care transitions" and "nephrology, nephrology nurse, dialysis and hemodialysis" (p. 339). No articles were found specific to handoffs in nephrology practice. As a result, Kear changed her focus from a systematic review to an integrative review to evaluate accepted definitions and evidence related to patient 
handoffs. Referencing 18 articles, Kear found that highly reliable organizations had communication tools and strategies as part of the organizations' structure. Healthcare must have effective communication which includes a standardized approach and the chance to exchange questions. The best handoffs occurred using a systematic approach such as SBAR. Nursing satisfaction, patient safety and patient satisfaction can be enhanced with clear and comprehensive patient handoffs (Kear).

\section{Improved Handoff Communication}

The Joint Commission defines a successful handoff as "a transfer and acceptance of responsibility for patient care that is achieved through effective communication" (2014, p. 2). Over the years, nurse to nurse handoff, also commonly known as nurse to nurse report, has occurred through a variety of methods including verbal handoffs, recorded handoffs and written handoffs. Information provided from one nurse to another may be given from a nurse's memory or using tools such as a structured report guide, written notes, the paper or electronic medical record. Additionally, the location of handoff has moved from the nurse's desk or breakroom to the patient's bedside. Adding a structure to patient care handoffs allows report to be concise and prompts the reporter to include key information preventing potential safety events due to lack of knowledge (Kear, 2016). To determine the structure, organizations must first determine the key elements that should be include in a hand off (Welsh, Flanagan, \& Ebright, 2010).

Welsh, Flanagan and Ebright (2010) performed a qualitative study to describe the written and taped handoff procedures. The researchers conducted semi-structured interviews asking 20 RNs and LPNs on three inpatient units about factors that facilitate and result in barriers of the nurse handoffs. Sixty-five percent of the interviewees used 
taped reports on their units and 35\% used written reports. Interview responses were coded by two reviewers and were classified as a barrier, facilitator or other. Six barriers were identified, including too little information, too much information, inconsistent quality, limited opportunity to ask questions, equipment malfunction and interruptions. Four facilitators were identified including pertinent content, notes and space for notes, face to face interaction with outgoing nurse and a structured format. Researchers also found that having the electronic medical record accessible to verify or locate missing information during handoff was beneficial. The researchers concluded that end of shift transfer consists of three steps: content transfer, clarification and inquiry and historical or chart review. Face to face interaction allows for questions, trust and opportunity feedback. To provide effective handoff, nurses must be given training, practice, evaluation and feedback (Welsh et al.).

A standardized reporting structure is only useful if staff believe in the benefit of the structure and embed it in their work culture. Fryman, Hamo, Raghavan, and Goolsarran (2017) performed a three-cycle quality improvement process with medical residents to implement a standardize report structure after poor unstructured handoff was found to be the cause of poor patient outcomes. The researchers compared the quality and error rates of a newly structured report with those of the conventional methods. The organization used the handoff mnemonic I-PASS which prompts the outgoing provider to report the patients' illness severity (I), patient summary (P), action list (A), situation (S), and prompts the receiving provider to synthesize $(\mathrm{S})$ the information received. Fifty residents participated in the study at Stony Brook University Hospital. Through surveys, the authors noted overall quality improvement and decreased medical errors with the 
implementation of I-PASS in the first cycle. Chi squared tests showed significant differences in the reported number of adverse events ( $\mathrm{p}=0.04)$, omitted code status $(p=0.003)$ and number of events that should have been reviewed but were not $(p=0.003)$ between the group using I-PASS and the group using conventional report. However, going forward the residents did not use I-PASS consistently. Therefore, the authors concluded that standardized reporting can improve the quality of handoff and decrease errors, but ongoing surveillance and feedback is needed to sustain practice change (Fryman et al.).

\section{Nurse to Nurse Bedside Report}

The literature supports performing nurse to nurse handoff at the patient's bedside. During bedside report, the ongoing and off-going nurse include the patient in report, thereby allowing the patient to ask questions and allowing the nurse to reconcile information received in report with a visual inspection of the patient and medical equipment in use. This practice increases patient safety through visual checks, increases patient satisfaction and includes the patient in the plan of care (Anderson \& Mangino 2006).

Maxson, Derby Wrobleski and Foss (2012) administered a survey to 15 staff nurses and a different survey, developed by the investigators, to 30 patients before and 30 patients after bedside report was implemented on an 11 bed surgical unit. The study aimed to determine if bedside nurse to nurse handoff improved the patients' satisfaction with the plan of care and perception of teamwork and the nurses' satisfaction with communication and accountability. Analysis of Likert surveys showed that beside report had a positive impact on patients and staff nurses. Patient scores increased post 
implementation related to feeling informed of the plan of care $(\mathrm{p}=0.02)$, feeling that there was open communication between the health care team and satisfaction at the amount of input patients were able to provide to the plan of care. Nursing scores increased related to feeling accountable $(\mathrm{p}=0.0005)$, communication between nursing staff at change of shift, ability to prioritize workload $(\mathrm{p}=0.06)$, performance of shift change medication reconciliation ( $\mathrm{p}=0.0003)$, and ability to communicate to physicians regarding patient care after nurse to nurse report $(\mathrm{p}=0.008)$. Patients appreciated the transparency of the care provided and nurses were better able to prioritize their care based on visual inspection of their patients during report (Maxson et al.).

Evans, Granawalt, McClish, Wood and Frieses (2012) performed a quality improvement project on a medical surgical unit in an acute care hospital. The project aimed to restructure and improve the process of nurse to nurse report. After a review of the literature, the team decided to perform verbal bedside report, guided by a script, with access to the electronic medical record. The team also decided that report time should be limited to 30-minutes total and include an environmental safety check. Nursing leadership kept a log book where they documented observations during the change process and conducted a survey of nursing staff to determine the staff's satisfaction and perception of the process change. The process change resulted in increased safety checks, decreased incremental overtime, increased patient participation in their care and increased nurse satisfaction. Report time decreased from 45-minutes pre-implementation to 29 minutes post implementation, allowing nurses to end shift on time and reduce incremental overtime. Nurses' satisfaction with report process increased from $37 \%$ to $78 \%$ post implementation. Leadership observations noted anecdotally that patients were 
more involved with their care and able to identify their caregivers for the shift which increased patient satisfaction. No statistics were provided to support this observation (Evans et al.).

One institution changed reporting practices from a completely recorded report to a blended recorded and bedside report. To measure the outcomes of this change, SandJecklin and Sherman (2014) surveyed patients and nurses regarding bedside report in three intervals, baseline, three months, and 13 months after the practice change. A total of 233 patients participated in the baseline survey, 157 participated in the three-month post implementation survey mark and 154 patients participated in the 13-month post implementation survey. Nurse participation included 148 nurses in the baseline survey, 98 in the three-month post implementation survey and 54 in the 13-month post implementation survey. In addition to the surveys, the authors evaluated the number of falls, medication errors and nursing overtime at the same intervals. Patients perceived more involvement in their care and improved nurse to nurse communication. Nurses perceived that bedside report prevented patient safety problems and increased nurse accountability and patient involvement. However, nurses also felt that bedside report took too much time to complete and were inconsistent in practicing bedside report. The survey results improved from baseline over the 13-month implementation but not significantly. Patient survey p-values by question ranged from $0.012-0.69$. The only question with a pvalue less than 0.05 was "made sure I knew who my nurse was." Nurse survey p-values by question ranged from $0-0.43$. Questions with a p-value less than 0.05 included: "report is effective means of communication," "report is efficient means of communication," "report helps assure accountability," "report is relatively stress free," "report helps 
prevent patient safety problems," and "report is completed in a reasonable time" (SandJecklin \& Sherman).

\section{Patient Centered Care}

With the movement toward patient centered care, standardization of report included not only the content of report but also the location of report. Reviewing the plan of care and allowing for a patient's input became an expectation and as a result patient handoff started shifting from a desk to the patient's bedside to allow patients to be active participants in their care (Anderson \& Mangino, 2006).

Timonen and Sihvonen (2000) surveyed 74 patients and 118 nurses in Finland who participated in bedside handoff reports on eight different surgical wards. The researchers used a four point Likert scale to compare nurses' and patients' opinions of bedside report, patient participation in report and factors that influence patients' participation in report. Handoff report was also observed by one of the nurses on the floors. The authors found that patients did not participate in the handoff as much as the nurses felt the patient participated. Eighty-three percent of the nurses $(n=98)$ compared to $52 \%$ of the patients $(\mathrm{n}=38)$ stated that report consisted of both nurses and patients taking part in the conversation. Timonen concluded that nurses should encourage patients to participate in bedside report so that patients can be active participants in their care (Timonen \& Sihvonen).

Tobiano et al. (2012) performed a qualitative case study interviewing eight family members regarding their perception of a bedside handoff report to investigate families' perception of beside handoff. The researchers categorized the transcripts into three main themes and thirteen subthemes which supported family centered care. Family members 
believed that bedside reporting allowed them to understand the patient's situation by allowing the family to be informed, understand the patient's condition and to become aware of the nursing plan of care. Bedside report allowed family members to interact with nursing staff to share information, clarify information, assist with patient care, ask questions, and to interpret information from nursing staff to the patient. Finally, family members found bedside handoff valuable because they felt included and were able to witness the individualism of patient care. Finally, Tobiano et al. found that allowing families to be involved in the handoff was an efficient way to allow families access to the patient's treatment plan. Family appreciate being part of the handoff and involving them can also improve the quality of the handoff by including the families' perspective.

\section{SBAR and SBARP}

The literature reveals multiple mnemonics that provide handoff structure by prompting providers to include key elements of information in their report. SBAR prompts the nurse to clearly communicate the current clinical situation, followed by a patient's pertinent background or history, assessment and recommendation. SBARP quickly developed to include the patient and bedside safety checks into the handoff.

To measure the impact of SBAR structure and interdisciplinary rounds on nurse handoff, Cornell et al. (2014) performed observational audits in three stages on 36 nurses who worked on a medical-surgical unit as they performed shift handoff using (1) preexisting methods for report, a paper SBAR tool and verbal format or (2) an electronic SBAR tool and verbal format. The observations showed that the total time spent in report increased when using the electronic SBAR and verbal format. At baseline, shift report took 14.3 minutes but increased to 21.5 and 25.4 minutes after implementation of the 
electronic tool. However, the SBAR tool helped increase the quality of report and prompted for more information to be passed between caregivers. However, the quality of information reviewed during handoff report also increased. Observation showed that information nurses reported was relevant, prioritized and essential instead of "top of mind information.” The SBAR structure allowed nurses to focus and give more relevant and prioritized information (Cornell et al.).

Nasarwanji, Nadr, and Gurses (2016) performed a qualitative analysis of 27 handoff mnemonics, 24 of which were found in a systematic review and three of which were identified in a database search. The researchers strived to compare and synthesize the information associated with each mnemonic. The 27 mnemonics, which included SBAR, were analyzed using content analysis and clustering. Each letter of the mnemonic was identified as a fragment. Of the 178 fragments, 108 were unique and fell into 12 main categories or themes. Situation, patient information, background and follow up care were four of the main categories identified which align with the four components of SBAR: situation; background; assessment; and recommendations. Clustering of the fragments also showed a four-level hierarchy, with information becoming more specific the higher the level in the hierarchy. The authors concluded that mnemonics have limited benefit, only guiding communication, but a mnemonic with a structured hand off tool could help improve communication and reduce errors. Therefore, organizations should perform local standardization of handoff process with staff input into the development process of the handoff (Nasarwanji et al.).

Achrekar et al. (2016) audited the completeness of 20 nurses' SBAR forms used for handoffs and distributed a survey to the nurses to determine their opinion on the 
SBAR tool. The SBAR documentation audits were performed in the first and $16^{\text {th }}$ week of the tool's use. Significant improvement was noted in the completeness of the SBAR form $(\mathrm{P}=0.045)$. Nurses found the SBAR structure very useful, but only $53 \%(\mathrm{n}=11)$ of the nurses thought involving the patient in documentation of the SBAR was necessary. However, the authors of the study concluded that incorporating the patient when completing the SBAR tool will help to push forward relevant information and reduce errors while establishing or increasing patient satisfaction (Achrekar et al.).

\section{Barriers to SBARP Report}

Despite the known benefits to nurse handoff at the bedside, staff are resistant to this practice. Anderson and Mangino (2006) conducted a quality improvement project to implement bedside report on a 32-bed adult acute care unit. In preparing for this change they noted that staff expressed concern that patient confidentiality would be compromised with bedside report. Staff also expressed fear that allowing patients to talk during report would increase the length of time of report. Staff were also concerned that they would not be able to talk freely in front of a patient because the patient may not know test results, may be uncompliant or maybe sleeping. After noting these concerns, the researches implemented bedside report. Staff and leadership made the change a priority. The nursing satisfaction was measured by surveying all staff ( $\mathrm{N}$ not provided) regarding the current report process pre-implementation and bedside report post implementation. Four patient satisfaction survey questions were identified to monitor, but only three were reported in the study because one question was dropped. Incidental overtime costs were also monitored pre-and post-implementation. 
Post implementation, incremental overtime decreased by 100 hours in the first four pay periods. The percentile scores for three patient satisfaction questions, "nurses kept you informed," "staff worked together to care for you," and "staff include you in decisions regarding treatment" were all above the $90^{\text {th }}$ percentile eight months post intervention. Nurses were asked to rate on a scale of 0-5 their feelings related to staff accountability for completing nursing care, their questions being answered before assuming care for patients, staff relationships between shifts, patient condition matching information received in report, report time being adequate, and report provided pertinent information related to the patient's condition. All scores on the nurse satisfaction survey increased from baseline to post implementation. Statistical significance was not analyzed. (Anderson \& Mangino).

Sherman, Sand-Jecklin, and Johnson (2013) performed a systemic review of bedside report articles. The search identified 42 articles, 12 of which met the inclusion criteria. Evaluation of the articles revealed nine out of twelve were qualitative studies with small sample sizes. However, sample size was not reported in all cases. Eleven of the articles reported a blended report style of bedside report and either recorded report or face to face report in a private area; one did not provide specific details related to the report locations. Perceived impairment of patient privacy and perceived increased length of report were barriers to bedside report implementation noted in one of the 12 articles. The results suggested that bedside report may lead to improved patient and nursing satisfaction. Because of the low number of publications, the authors speculated that other facilities may not have published bedside handoff findings due to negative results or failed implementation (Sherman et al.). 
Taylor (2015) performed a qualitative survey of 17 nurses on a surgical oncology unit four years after bedside handoff was implemented. Taylor's aim was to determine how a standardized handoff can improve patient safety and satisfaction. Taylor found that although the majority of the nurses were at least moderately satisfied with bedside handoff and walking rounds, the walking rounds were not always completed. Unit distractions, including call bells, phone calls and prioritization of clinical needs prevented staff from consistently performing walking rounds. Nurses also felt that patient privacy was impaired when performing bedside handoff and time constraints prevented bedside handoff and walking rounds.

\section{Benefits of SBARP Report}

Anderson and Mangino (2006) measured the benefits of implementing bedside report on an adult acute care unit by monitoring incidental overtime, patient satisfaction surveys and nurse satisfaction surveys. As reviewed earlier, despite the initial concerns of staff, the researchers found that bedside report decreased incremental overtime by over 100 hours in the first two pay periods after the implementation of bedside report and patient satisfaction scores steadily increased reaching the $90^{\text {th }}-100^{\text {th }}$ percentile in the post implementation data collection period. For the question "how well the nurses kept you informed," five out of the eight data points were in the $90-100^{\text {th }}$ percentile post intervention compared to one of four data points pre-intervention. For the question "how well staff worked together to care for you" six of the eight data points were in the $90^{-}$ $100^{\text {th }}$ percentile post intervention compared with two out of four data points preintervention. For the question "staff effort to include you in decisions about your treatment," five out of eight data points were in the $90-100^{\text {th }}$ percentile pre-intervention 
compared with zero of four data points preintervention. Staff satisfaction increased due to improved teamwork. The chief nursing officer anecdotally reported to nursing leadership that physician satisfaction increased because they felt nurses were more informed after the implementation of bedside report.

Patient safety also increases with the implementation of SBARP report. In a study previously reviewed, Taylor (2015) found that after implementing walking rounds and bedside handoff, the number of falls with injuries on the unit decreased from five falls with injury pre-implementation to three falls with injury post implementation. However, it is important to note that the total number of falls increased from 25 to 29 and the number of medication errors decreased.

Tobiano et al. (2012) explored family members' perception of bedside handoff in an adult rehabilitation unit. Eight family members were interviewed and family interactions during bedside report were observed. Interviews were recorded and transcribed and non-verbal interactions were recorded in field notes. Data were categorized into themes and subthemes. Three themes and 13 subthemes emerged from the family members' perception of the bedside handoff. The first theme of understanding the situation had three subthemes including feeling informed, understanding the patient's condition and understanding the patient's treatment. The second main them, interacting with nursing staff, had five subthemes including sharing information, clarifying information, assisting with care, asking questions and interpreting for the patient. The third main theme, finding value in information provided during handoff, also had five subthemes including feeling at ease, feeling included, valuing individualism, preparing for the future and maintaining patient privacy. The researchers concluded that patients 
and families feel they can improve the accuracy of information transferred during handoff report (Tobiano et al.)

Cairns, Dudjak, Hoffmann and Lorenz (2013) evaluated the effects of implementing a bedside shift report on end of shift overtime, call light usage during shift report and patients' perception of being involved in their care on a 27-bed unit. The researchers also administered a seven-question survey to evaluate staff satisfaction. Twenty-nine staff nurses responded to the pre-implementation survey and 18 nurses responded to the post implementation survey. Three months after implementation of bedside report, call light usage decreased by 33\% during report and nurses believed report was more concise and the mean patient satisfaction scores increased. Press Ganey survey results increased two months post implementation. The score for the question "nurses kept you informed" increased from 88.9 to 91.1. The score for the question "staff included you in decisions related to treatment" increased from 79.7 to 83.9 two months after bedside report was implemented (Cairns et al.).

Next, the theoretical framework will be presented. 


\section{Theoretical Framework}

Rogers' Diffusion of Innovation theory will be used to guide the development and implementation of this project. Roger's describes five phases over which a new idea takes shape: knowledge, persuasion, decision, implementation and confirmation. Knowledge occurs when a new idea is formed. Persuasion is the process in which a person or group of people seek more information about the new idea. Once the benefits and disadvantages of the idea are considered a decision is made whether or not to adopt the idea. Implementation occurs when the idea is set into motion, and finally confirmation occurs when a person or group decides to continue with the idea (Rogers, 2003).

Rogers (2003) described an idea's characteristics including relative advantage, compatibility, degree of complexity, trialability and observability and how these contribute to the decision to adopt an idea. Relative advantage is the amount an idea is viewed as an improvement over the current situation. Compatibility describes how easily a new idea can fit into current practice. Degree of complexity defines how easily a new idea can be adopted. Trialability describes how easily an idea can be trialed before it is adopted. Observability is the extent to which an idea can produce visible results (Rogers, 2003).

Rogers (2003) also identified six categories in which to classify idea adaptors including the innovator, early adaptor, early majority, late majority and laggards. Innovators are commonly the risk takers and the first to adopt to a new idea. Early adaptors tend to be more educated than the innovators. They are aware a change needs to occur and are willing to try new ideas. Early majority adopt new ideas before the average person, but are not typically leaders. The early majority needs to see proof than an idea 
will work and is successful before conforming to the idea. The late majority are often skeptical of and will adopt an idea only after the majority of the population has tried the plan. Finally, the laggards are the people who are the last to change. Laggards are often deeply set in their traditions and a resistant to adopting a new process (Rogers). It seems that nurses with less years of experience were the early adaptors and early majority when adopting a bedside handoff. However, they are influenced by the more experienced nurses who tended to be the late majority and the laggards.

In 2010, Lifespan made the decision to implement bedside report. The idea developed to improve patient satisfaction scores and improve patient safety through bedside safety checks. The organization addressed perceived disadvantages such as infringement of patient privacy and longer report times through staff education (Dufault et al., 2010). Lifespan as an organization has reached the implementation stage of SBARP: the idea has been implemented, with varying success, and the idea will continue to be an expectation of staff. Despite management's commitment to SBARP handoff at the bedside, staff nurses do not seem to share the same commitment as evidenced by antidotal poor compliance with the process (Dufault, 2017). Therefore, this project will attempt to identify staff nurses' perceived barriers to bedside SBARP handoff in an attempt to gain insight on why the idea has not reached the confirmation stage.

Lifespan as a corporation believes the relative advantage of bedside report is positive. It will increase patient satisfaction and patient safety. However, anecdotally staff nurses can see some benefits but also note negative aspects of bedside report, including longer report times, infringement in patient privacy and difficulty discussing sensitive information in front of a patient. Bedside handoff is not complex and is easy to trial 
because the only change to the handoff is the location of report and the addition of safety checks.

The SBAR reporting structure has been in use at Lifespan for over 11 years. Handoff at the bedside was introduced at Lifespan seven years ago. However, despite education and re-education, staff compliance with performing handoff at the bedside is varied. It seems staff may fall into Roger's late majority and laggard category due to perceived barriers to performing handoff at a patient's bedside. Although the degree of complexity, trialability and observability of SBARP at the bedside may be easy, staff may not perceive the relative advantage of performing SBARP handoff at the bedside verses at the nurse's station or outside of the room.

Next, the methods will be reviewed. 


\section{Method}

\section{Purpose}

The purpose of this study was to identify nurses' perceived barriers to performing SBARP (Situation, Background, Assessment, Recommendation and Patient) at the bedside in an acute care setting.

\section{Design}

A mixed qualitative and quantitative survey (Appendix A) was utilized to assess the nurses' perceived barriers to performing SBARP at the patient's bedside.

\section{Sample and Site}

The survey took place at Newport Hospital, a community hospital in Newport RI. The hospital is licensed for 129 beds across many acute care service lines including medical surgical patients, critical care, maternity, labor and delivery, inpatient rehab and inpatient behavioral health. The sample for this study was the medical surgical staff nurses at Newport Hospital who work on two medical-surgical floors: Tower 2 and Tower 4. All staff nurses and all shifts were eligible to participate in the survey including nurses who float to these areas. Nurse managers, assistant nurse managers and educators were not included in the sample. The response rate goal was set at $30 \%$ of the total staff nurses on both units.

\section{Procedures}

This project was approved by nursing leadership at Newport Hospital, including the manager of the education department and the chief nursing officer (Appendix B). Leadership on Tower 2 and Tower 4 also agreed to participate. A survey was developed guided by the literature review and reviewed by peer RNs for readability and clarity 
(Appendix A). The project was submitted and determined to be exempt by the Institutional Review Board (IRB) at Newport Hospital and Rhode Island College.

Staff were informed of the purpose of the survey and timeframe in which to complete the surveys through email (Appendix C) and through verbal announcement at staff meetings, and huddles (Appendix D). Paper copies of the survey with an informational letter (Appendix E) attached to each survey were distributed to Tower 2 and Tower 4 by being left in a central location recommended by the units' clinical leadership. A sealed box in which completed survey were to be placed was located on each of the units.

Staff were initially given two weeks to complete the survey. A reminder email was sent from the managers at the end of the first week. Because after the second week participation was less than $30 \%$ of the potential participants, the surveys were left available for one more week with a second reminder email sent. As incentive, the unit with the highest rate of participation was promised to be rewarded with a basket of candy.

Surveys were collected at the end of the initial two-week period by this researcher and after the third week. Surveys were kept in a locked desk drawer in a locked office and were shredded upon completion of the project.

\section{Measurement}

A survey was developed guided by survey questions found in the literature review. Maxson, Derby, Wrobleski, and Foss (2012), Sand-Jecklin and Sherman (2014), and Timonen and Sihvonen (2000) wrote three influential articles that listed examples of survey questions related to beside handoff. These examples helped to direct the survey created for this project. Positive and negative versions of each question were written to 
assess reliability since the validity of the survey is not established. The survey was piloted by two co-workers for readability. Each coworker stated they were able to understand the intent of the survey and were not confused by the wording of the questions. They also said they would feel comfortable completing the survey.

The survey has a total of 17 questions: two open ended; 12 with a Likert scale; and three questions in which the respondent circled their response. One of these questions collected the demographic data of years of experience as an $\mathrm{RN}$ of the respondent.

\section{Data Analysis}

Reponses were reviewed based on years worked as an $\mathrm{RN}$ and by average score. The Likert responses were tallied and averaged (Appendix F). The positive and negative questions were examined for consistency of responses. Negative items were reverse scored prior to obtaining means. The means of those scores were then compared to the positive version of the question. Qualitative responses were reviewed for similar themes and classified as positive, negative or mixed feelings toward bedside handoff (Appendix G).

\section{Evaluation Plan}

The survey was considered successful if a 30\% participate rate was obtained and if the survey revealed barriers to bedside handoff that could be addressed in future projects.

Next, results will be reviewed. 


\section{Results}

The survey was made available in the breakroom of Turner 2 and Turner 4 on Wednesday, February $28^{\text {th }}$. After two weeks of availability, there was only a $25 \%(n=$ 19) response rate. The survey was made available for an additional week but no additional responses were received. Of the 19 respondents, nine nurses (47\%) had 1-5 years of experience as a nurse, four respondents (21\%) had 6-10 years of experience, and six respondents $(32 \%)$ had 11 or more years of experience as a nurse.

In addition to the demographic information, nurses were asked two questions related to reporting at the bedside. Next, the survey included two open ended questions to determine nurses' perceived barriers to bedside handoff and 14 Likert response questions. Key findings are presented below.

Figure 1 on the next page illustrates nurses' responses to the question: "What percentage of time do you perform nurse to nurse patient handoff at the patient's bedside?" 


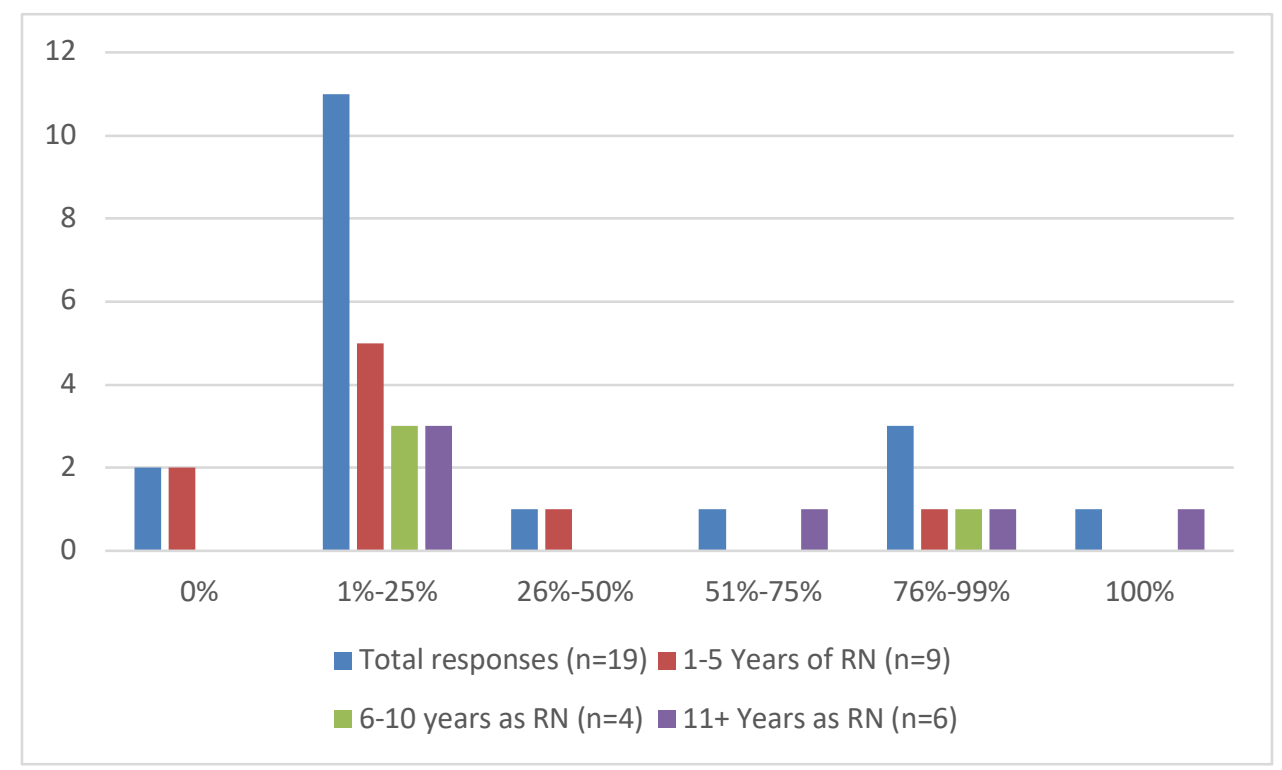

Figure 1. Reported percentage of the time nurse to nurse handoff is performed at the patient's bedside.

The majority of respondents $(\mathrm{n}=11 ; 58 \%)$ overall and within each category of years of experience stated they performed handoff at the patients' bedside $1-25 \%$ of the time.

Nurses were also asked: "If you do not perform handoff at the bedside $100 \%$ of the time, where do you give report"? Responses as illustrated in Figure 2 on the next page. 


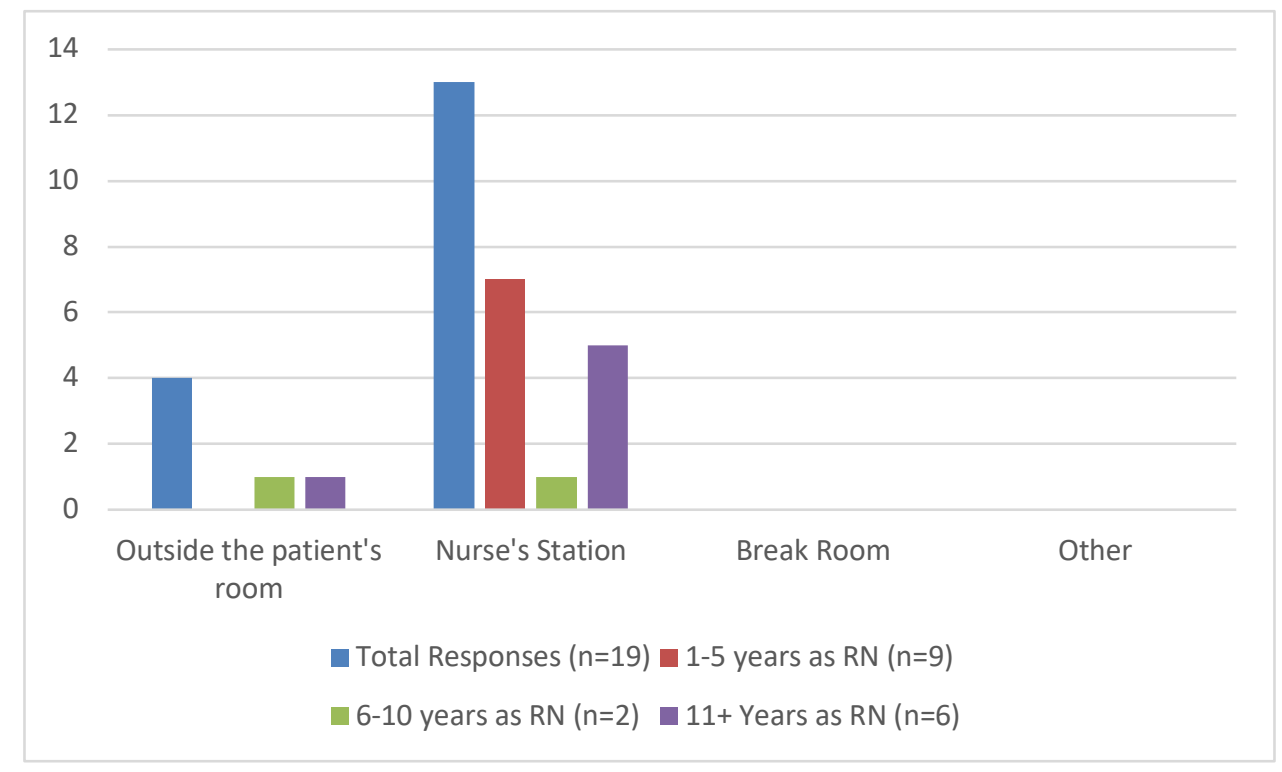

Figure 2. Location of handoff

Thirteen out of $17(76 \%)$ respondents indicated that patient handoff occurred at the nurses' station. This was also the most frequent response in each years of experience category. No respondent indicated any other location or that they gave report in the breakroom. It is important to note that two respondents in the 6-10 years of experience group circled two options and those data were omitted.

Respondents were also asked two open ended questions. The first question was: "Please identify why you perform full SBARP report at the patient's bedside". See Table 1 on the next page for a full list of responses. 
Table 1

Responses to the Question: "Please identify why you perform full SBARP report at the patient's bedside."

\begin{tabular}{|c|c|c|}
\hline Positive & Mixed & Negative \\
\hline $\begin{array}{l}\text { To make sure patient is okay, } \\
\text { if they need anything they } \\
\text { are in pain, so that they know } \\
\text { what is going on }\end{array}$ & $\begin{array}{l}\text { I try to combine the } \\
\text { approach. Do a quick } \\
\text { report at the nurse's } \\
\text { station with computer } \\
\text { then go into room and } \\
\text { answer quick questions } \\
\text { and make sure the patient } \\
\text { is ok }\end{array}$ & $\begin{array}{l}\text { I prefer report at nurses' station } \\
\text { where details can be reviewed } \\
\text { thoroughly }\end{array}$ \\
\hline $\begin{array}{l}\text { Give patient the opportunity } \\
\text { to ask questions and clarify } \\
\text { info during } \mathrm{RN} \text { handoff }\end{array}$ & & Because we were told we have to \\
\hline Decrease time giving report & & $\begin{array}{l}\text { MDs don't even tell patient's } \\
\text { families what's going on and why. } \\
\text { Puts RN on spot when family asks } \\
\text { questions before reading chart }\end{array}$ \\
\hline $\begin{array}{l}\text { To give next RN a complete } \\
\text { report including the patient } \\
\text { helps keep them updated on } \\
\text { current plan of care and tests }\end{array}$ & & Because that is the new protocol \\
\hline $\begin{array}{l}\text { Include patient, look at safety } \\
\text { stuff, handoff }\end{array}$ & & \\
\hline $\begin{array}{l}\text { Monitor correct fluids } \\
\text { infusing }\end{array}$ & & \\
\hline $\begin{array}{l}\text { To keep patient's informed, } \\
\text { check dressings, IVF, tubing } \\
\text { labels, high risk med } \\
\text { infusions (PCAs), to check } \\
\text { bed alarms, safety measures, } \\
\text { decrease time/questions } \\
\text { compared to if done at } \\
\text { nursing station, decrease call } \\
\text { bells at change of shift }\end{array}$ & & \\
\hline \multicolumn{3}{|l|}{$\begin{array}{l}\text { Prevent falls, include the } \\
\text { patient in the plan of care }\end{array}$} \\
\hline $\begin{array}{l}\text { Continuity of care, patient } \\
\text { safety, decreases patient } \\
\text { anxiety }\end{array}$ & & \\
\hline
\end{tabular}


Seven of the 19 participants (37\%) left this question blank. Of the 12 participants who responded, nine (75\%) identified positive benefits of beside handoff, including safety checks of equipment, involving the patient in the plan of care, and decreasing time spent in report. Four responses were categorized as negative. Two respondents answered that they performed bedside report because of a protocol or they were told it was required.

Respondents also stated that it is difficult to speak openly in the patients' rooms during bedside report. One response was categorized as mixed. The respondent indicated that a handoff occurring initially at the nurses' station but ending in the patients' room was beneficial to access the computer at the nurses' station and to then incorporate the patient briefly.

The second open ended question, "Please list some barriers to performing SBARP at the patient's bedside" yielded 17 responses. Table 2, on the next page, lists the responses; those that could not be categorized as a barrier were not included. 
Table 2

Reported Barriers to Performing SBARP at the Bedside

\begin{tabular}{|c|c|}
\hline Theme & Response \\
\hline Privacy & $\begin{array}{l}\text { Sensitive Information } \\
\text { Privacy (x2) } \\
\text { HIPPA (x2) and sensitive Information being discussed } \\
\text { Invasion of privacy (double rooms) }\end{array}$ \\
\hline Time & $\begin{array}{l}\text { Takes much longer to give report at bedside } \\
\text { Certain patients would want too many things done } \\
\text { Definitely in the AM having patients request toileting, food, } \\
\text { ect. } \\
\text { Patients interrupting for things impact speed and efficiency } \\
\text { of report } \\
\text { Anxious need patients } \\
\text { Takes forever } \\
\text { Patient talks during report } \\
\text { Patient requests items during report } \\
\text { Certain personalities can pro-long the report giving process } \\
\text { Length of time nurses take to be ready for report (on and off } \\
\text { going) }\end{array}$ \\
\hline Patient Characteristics & $\begin{array}{l}\text { Older patients - hearing difficulty } \\
\text { Precautions room }\end{array}$ \\
\hline Test Results & $\begin{array}{l}\text { Sensitive issues / diagnosis } \\
\text { Test results that MD haven't told patient } \\
\text { Sensitive issues } \\
\text { Results of certain tests should be made more private }\end{array}$ \\
\hline Sleeping & $\begin{array}{l}\text { Disrupting patient's sleep } \\
\text { Patient's sleeping or napping, don't get enough sleep as it is } \\
\text { Sleeping } \\
\text { Sleeping patients } \\
\text { Patients are sleeping }\end{array}$ \\
\hline Information Availability & Unable to look something up if needed \\
\hline Patient Request not to & Patients refuse \\
\hline Visitors & $\begin{array}{l}\text { Others in room } \\
\text { Family in room } \\
\text { Family visitors in room }\end{array}$ \\
\hline Nurse Comfort & $\begin{array}{l}\text { Awkward } \\
\text { Resistance from staff }\end{array}$ \\
\hline Leadership & $\begin{array}{l}\text { Resistance from staff } \\
\text { Lack of enforcement from managers } \\
\text { Compliance of all nurses } \\
\text { People not wanting too }\end{array}$ \\
\hline $\begin{array}{l}\text { Not comfortable } \\
\text { discussing in front of } \\
\text { patient }\end{array}$ & $\begin{array}{l}\text { Can't say everything in front of patient } \\
\text { Psych problems }\end{array}$ \\
\hline
\end{tabular}


Responses were reviewed and categorized into main themes by the researcher. These de-identified responses and themes were then provided to a co-worker to review. The co-worker agreed with the theme categories, supporting the researcher's review. Respondents listed a total of 41 replies to performing bedside report that were categorized into ten barrier-related themes.

Figure 3 below displays the frequency of each barrier identified.

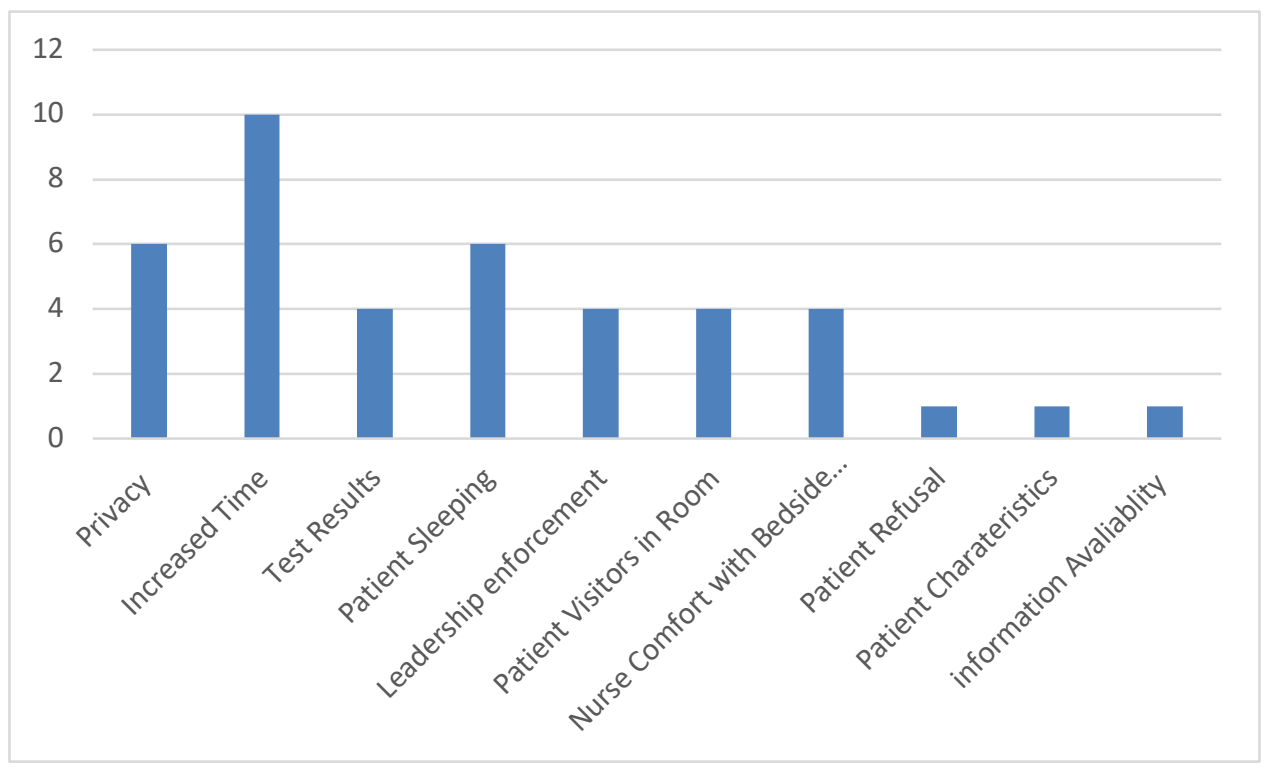

Figure 3. Barriers to performing bedside report $(\mathrm{n}=13)$

The perception that bedside handoff would increase the time spent in nurse to nurse report was the most common barrier identified. Rated equally was the perception that patients' privacy would be violated during bedside handoff and that patients did not wish to be awakened for bedside handoff. Respondents mentioned the themes of leadership enforcement of bedside handoff, patient visitors, nurse comfort with the bedside handoff practice, and hesitancy to discuss sensitive test results as the third most common barriers to performing bedside handoff. 
The survey contained 14 Likert questions for respondents to rate on a scale of 1 (strongly disagree) to 5 (strongly agree). Table 3 lists the mean responses. The mean responses are displayed in columns, with the overall mean in the first column and then means by years of experience as RN in the subsequent columns.

Table 3

Barriers Survey Mean Scores: Overall $(N=19)$ and by Years of Experience

\begin{tabular}{|c|c|c|c|c|}
\hline Number of Years as RN & Overall & $1-5$ & $6-10$ & $10+$ \\
\hline $\begin{array}{l}\text { Bedside report decreases the length of } \\
\text { time I spend in report }\end{array}$ & 2.72 & 2.5 & 3 & 2.67 \\
\hline $\begin{array}{c}\text { Patients do not mind being interrupted for } \\
\text { bedside report }\end{array}$ & 2.72 & 3.13 & 3 & 2.17 \\
\hline $\begin{array}{l}\text { Bedside report in a double occupancy } \\
\text { room does not violate a patient's privacy }\end{array}$ & 1.68 & 2.44 & 1 & 1 \\
\hline $\begin{array}{c}\text { In general patients interact appropriately } \\
\text { during bedside report }\end{array}$ & 3.56 & 3.63 & 3.5 & 3 \\
\hline $\begin{array}{l}\text { Sensitive test results should not be } \\
\text { discussed during beside report }\end{array}$ & 4.11 & 3.44 & 5 & 4.5 \\
\hline $\begin{array}{l}\text { Bedside report helps prevent patient safety } \\
\text { problems }\end{array}$ & 4.16 & 3.77 & 3.75 & 4.17 \\
\hline $\begin{array}{l}\text { Patient requests cause bedside report to } \\
\text { take longer }\end{array}$ & 3.42 & 4.33 & 3.75 & 2.67 \\
\hline $\begin{array}{l}\text { Including the patient in bedside report } \\
\text { increases patient satisfaction }\end{array}$ & 3.47 & 3.56 & 3.5 & 3.33 \\
\hline $\begin{array}{c}\text { Bedside report in double } \\
\text { occupancy rooms violates a patient's } \\
\text { privacy }\end{array}$ & 4.68 & 4.33 & 5 & 5 \\
\hline $\begin{array}{l}\text { Any test result can be discussed during } \\
\text { bedside report }\end{array}$ & 1.63 & 2.11 & 1.25 & 1.5 \\
\hline $\begin{array}{c}\text { Patients do not want to be interrupted for } \\
\text { bedside report }\end{array}$ & 2.84 & 2.89 & 2.25 & 3.17 \\
\hline $\begin{array}{l}\text { Bedside report increases patient } \\
\text { involvement in care }\end{array}$ & 4.16 & 4.22 & 4.5 & 4 \\
\hline $\begin{array}{l}\text { Bedside report does not impact patient } \\
\text { safety }\end{array}$ & 2.37 & 2.5 & 2 & 1.83 \\
\hline $\begin{array}{c}\text { Patients' satisfaction is not impacted by } \\
\text { bedside report }\end{array}$ & 2.26 & 2.44 & 1.75 & 2.33 \\
\hline
\end{tabular}


Some responses from the Likert questions were closely related to the perceived barriers identified in the open-ended question. Increased time of report related to beside handoff and patients' privacy were the two most frequently cited barriers in the openended questions. Survey results show that respondents felt strongly that bedside report in double occupancy rooms violates a patient's privacy $($ mean $=4.68)$, which was also the highest average response of all questions. Responses to the question that sensitive test results could not be discussed in front of the patient during bedside handoff was the third highest $($ mean $=4.11)$.

Nurses responded with a mean of 3.42 in response to the statement that bedside report increases the length of time spent in handoff, despite listing this theme as a barrier 11 times in the open-ended question. Nurses leant slightly toward disagree with the response to the questions patients do not want to be interrupted for bedside report (mean $=2.84$ ), despite listing patient sleeping six times and visitors in the patient's room four times as a barrier in the open-ended questions.

Staff nurses also acknowledged that patient safety and patient satisfaction can be positively impacted by bedside handoff. Average response to the question "Bedside report helps prevent patient safety problems was 4.16, which was the second highest score. Average response to the question "Bedside report increases patient involvement in care" tied for the second highest overall score (mean =4.16). Average response to the question "Including the patient in bedside report increased patient satisfaction" was 3.47. Responses were only slightly toward "agree" which may relate to the identified barrier of lack of leadership enforcement. 
Appendix F contains the number of responses overall and by years of experience to each demographic question on the survey, including the demographic questions, average scores and reverse scores where applicable to the Likert questions.

Most of the Likert questions had a positive and negative version to examine consistency between them. The mean of the reverse or inverse scores were calculated for the negative questions and compared to the mean score of the positive questions. Table 4 on the next page displays the positive and negative version of each applicable question and the difference between responses.

Table 4

Positive and Negative Likert Question Means and Difference Scores

\begin{tabular}{|l|l|l|}
\hline $\begin{array}{l}\text { Positive Question with } \\
\text { Overall Mean Score }\end{array}$ & $\begin{array}{l}\text { Negative Question with } \\
\text { Overall Mean Score* }\end{array}$ & Difference Score \\
\hline $\begin{array}{l}\text { Bedside Report decreases } \\
\text { the length of time I spend } \\
\text { in Report; Mean }=2.72\end{array}$ & $\begin{array}{l}\text { Patient requests cause } \\
\text { bedside report to take } \\
\text { longer; Mean =1.84 }\end{array}$ & 0.88 \\
\hline $\begin{array}{l}\text { Bedside report in double } \\
\text { occupancy rooms violates a } \\
\text { patient's privacy; Mean }= \\
\text { 4.68 }\end{array}$ & $\begin{array}{l}\text { Bedside report in a double } \\
\text { occupancy room does not } \\
\text { violate a patient's privacy; } \\
\text { Mean =4.32 }\end{array}$ & 0.36 \\
\hline $\begin{array}{l}\text { Sensitive test results should } \\
\text { not be discussed during } \\
\text { bedside report; Mean }= \\
\text { 4.11 }\end{array}$ & $\begin{array}{l}\text { Any test result can be } \\
\text { discussed during bedside } \\
\text { report; Mean =4.26 }\end{array}$ & -0.15 \\
\hline $\begin{array}{l}\text { Bedside report helps } \\
\text { prevent patient safety } \\
\text { problems; Mean }=4.16\end{array}$ & $\begin{array}{l}\text { Bedside report does not } \\
\text { impact patient safety; } \\
\text { Mean =3.54 }\end{array}$ & 0.62 \\
\hline $\begin{array}{l}\text { Patients do not mind being } \\
\text { interrupted for bedside } \\
\text { report; Mean = 2.72 }\end{array}$ & $\begin{array}{l}\text { Patients do not want to be } \\
\text { interrupted for bedside } \\
\text { report; Mean = 2.58 }\end{array}$ & 0.14 \\
\hline $\begin{array}{l}\text { Including the patient in } \\
\text { bedside report increases } \\
\text { patient satisfaction }-3.47\end{array}$ & $\begin{array}{l}\text { Patients' satisfaction is not } \\
\text { impacted by beside report } \\
\text { 3.74 }\end{array}$ & -0.27 \\
\hline
\end{tabular}

*Average scores listed to negative questions were calculated with reverse scoring 
Differences between the positive and negative Likert questions ranged from -0.15 to 0.88 . The largest differences were between the question "Bedside report decreases the length of time I spend in report" and "Patient requests cause bedside report to take longer". Respondents may have perceived these questions as addressing different causes of increased time spent in report. The questions addressing patient safety, sensitive test results, and patients' preference to be interrupted had the smallest difference scores, suggesting that respondents' responses to these questions were consistent and reliable.

Interestingly, the questions related to patient privacy had a difference score of 0.36. However, when reviewed by years of $\mathrm{RN}$ experience, there was no difference in response for nurses with 6-10+ years of experience. All nurses in these two categories strongly agreed that bedside report in a double occupancy room violates a patient's privacy. Nurses with 1-5 years of experience was the only category where respondents did not select all "strongly agree" for this question.

Next, summary and conclusions will be presented. 


\section{Summary and Conclusions}

The Joint Commission (2007) cited communication as a leading cause of sentinel events and that using a clear standardized manner of communication increases patient safety. Literature also supports that including the patient in the plan of care increases patient satisfaction. Kaiser Permanente introduced the standardized format of situation, background, assessment and recommendation, or SBAR, to better ensure clear and focused communication between healthcare providers using this tool (Kaiser Permanente, 2007).

As healthcare became more patient focused, the location of nurse to nurse handoff shifted from the nurses' station to the patients' bedside, allowing the patient be more involved in the plan of care. Including the patient in shift handoff has been shown to increase patient satisfaction with care and nurse job satisfaction (Maxson et al., 2012). Despite proven benefits of bedside handoff, some nursing staff remain resistant to this practice. Multiple barriers are cited in the literature, including nurses' perception of impaired patient privacy, time constraints, and unit distractions including call bells, competing clinical priorities, and phone calls (Taylor, 2015).

Lifespan, including Newport Hospital, implemented the SBARP systematic approach to bedside handoff and rolled the practice out as a high priority initiative. Despite the organizational support for bedside handoff, only 1 of $19(5 \%)$ of survey respondents indicated that they perform bedside report $100 \%$ of the time. Thirteen of 19 respondents (68\%) responded that they performed bedside handoff $25 \%$ of the time or less. 
The perception that a patient's privacy would be impaired if report was given in a double occupancy room was the most common barrier identified in the open-ended questions. This was surprising considering that only seven of the fifty rooms on Turner 2 and 4 are double occupancy rooms and they are only doubled when needed due to census. When reviewing the survey results broken down by the number of years worked as an $\mathrm{RN}$, it was surprising to see that nurses with one to five years of experience did not feel as strongly as nurses with six or more years of experience that report in a double occupancy room negatively impacts patient privacy. Nurses with less than 6 years of experience also did not feel as strongly as nurses with six or more years of experience that sensitive test results should not be discussed during report. This seems to suggest, based on this limited sample, that the newer generation of nurses are more comfortable performing bedside handoff in a double occupancy room. This could be related to increased awareness in nursing school of the expectation to perform a systematic bedside handoff with the patient. Nurses with less experience are closer to their didactic lessons where they may have been taught to perform bedside handoff as well as tactics to address privacy and ethical concerns from the start of their nursing career. In contrast, for more experienced nurses, handoff has evolved from the desk to the bedside. Nurses with more experience may also be more sensitive to privacy and ethical concerns preventing them from feeling comfortable to perform a full bedside handoff.

The responses to the open-ended questions suggested that leadership has a role in promoting and enforcing bedside handoff. Two respondents answered that they performed bedside report because of a protocol or that they were told it was required. Furthermore, three respondents wrote that lack of enforcement from managers and staff 
nurse compliance were barriers to performing bedside handoff. Leadership monitoring and re-enforcement of expectations and benefits of bedside handoff may help to hardwire the practice. Perhaps with more leadership encouragement and oversight of the process, staff nurses would also be more able to translate bedside handoff to increased nurse satisfaction.

Nurse comfort with performing bedside handoff was cited frequently in the openended question response and throughout a variety of themes. Staff reported that they felt “awkward" performing bedside report. Staff also reported that discussing sensitive test results, "psych problems," and discussing "drug seeking” behaviors result in a barrier to performing beside handoff. Providing staff with scripting and methods that could be used to discuss sensitive information may reduce the occurrence of this barrier.

Out of a potential 76 medical surgical staff nurses in the float pool, Turner 2, and Turner 4, only 19 (25\%) responded to this survey. Because of the small sample size, it is difficult to determine if the results are representative of the staff nurses overall. Also, at the time of the survey distribution, there was a separate project on Turner 4 to reinvigorate bedside report that included a separate survey and educational poster listing the benefits of bedside handoff. This may have impacted survey results by providing publicized benefits of bedside handoff. Because the survey for this study was released soon after the first survey, response rates for this study may have been negatively impacted.

The goal of this project was to identify nurses' perceived barriers to performing bedside handoff. The survey results indicated that nurses' comfort level, perceived length 
of bedside report, and patient privacy are significant barriers to performing bedside report. These themes are similar to barriers discussed in the literature review. Despite these barriers, staff nurses did acknowledge that bedside report positively impacts patient satisfaction, allows for safety checks of the patient and medical equipment, and increases the patients' involvement in their plan of care. Focusing on these agreed upon benefits and evidence from the literature, along with education targeted to dispel the identified barriers, may help increase t compliance with bedside reporting.

Next, recommendations and implications for advanced nursing practice will be discussed. 


\section{Recommendations and Implications for Advanced Nursing Practice}

Sustaining any long-term change requires vigilance and work from nursing staff and leadership. Nursing staff need to understand and believe that the change will benefit them and their patients and leaders must role model expectations and reinforce the benefits of the desired practice. Advanced Practice Nurses (APRNs) are prepared to help identify the need for change and help to sustain the change over time. The clinical nurse specialist (CNS) is trained to perform a needs assessment and to identify when a previously implemented practice change is no longer being sufficiently and effectively sustained. Through the needs assessment, the CNS may also identify reasons that the change has not been sustained.

The CNS can use information from the needs assessment to develop targeted education. For example, the CNS can include support from the literature and quality data showing the benefits of bedside reporting to nurses and patients. The CNS could actively develop scripts that staff nurses could use during report to ease their discomfort in discussing sensitive information in front of the patient and significant others. The CNS may also organize and facilitate role playing simulations in which the staff nurse could practice bedside report in front of a patient actor.

The CNS also may serve as a formal and informal leader. As a leader, the CNS can assist clinical leadership in supporting the expectation of bedside handoff. The CNS may perform audits to measure the staff nurses' compliance performing bedside report and provide direct feedback to staff nurses. As an informal leader, the CNS may help guide staff through the change process. The CNS may facilitate open conversations to 
help staff talk through their feelings about the change, both positive and negative. The goal would be to help staff nurses to feel supported that they can discuss their concerns and also hear counter arguments. By emphasizing evidence presented in the literature and illustrating how to translate it into practice, the CNS could be instrumental in supporting and sustaining the practice change.

In intervening in this situation, the CNS is utilizing each sphere of the Synergy Model: the patient; the nurse; and the system. The CNS aims to improve the patient experience, satisfaction, involvement and understanding of the plan of care by supporting bedside report. The CNS supports the staff nurse through education, leadership, and role modeling. The system's change and priority to implement bedside handoff is being supported which will lead toward attainment of organizational priorities such as improved patient satisfaction scores and nurse satisfaction scores. Furthermore, support of nurse to nurse bedside handoff may potentially evolve into more interdisciplinary bedside rounding practices. Once the benefits of nurse to nurse bedside handoff are realized, the organization may apply the idea of bedside, patient-centered rounding to other practices such as interdisciplinary collaborative care rounds or provider handoff.

The CNS can share successes and opportunities with other healthcare facilities or APRNs through presentations, publications, or informal consultations. Organizations may incorporate the expectation of bedside handoff into policy and procedure. Through participation in national organizations the CNS will also be able to disseminate best practices nationally. The CNSs' advocacy to include the patient in the plan of care and increase patient safety through bedside report could be advanced to become a position statement or suggested requirement in CNS or ANA practice guidelines. 
Further research will be needed once bedside handoff is hardwired to measure compliance with the practice and also measure empirical outcomes such a patient and nurse satisfaction as related to bedside handoff. The APRN could use patient satisfaction surveys pre and post bedside handoff implementation to measure the benefits of the practice change. Incremental overtime pre and post implementation can be monitored to determine whether or not bedside handoff has increased the time spent in handoff. Visual audits and monitoring of the practice will help to determine the quality of report and how involved the patient is in nurse to nurse bedside handoff. Lastly, interviews of patients and nurses could help to qualitatively measure the patients' and nurses' perception of the benefits or frustrations with the practice of SBARP. 


\section{References}

Achrekar, M.S., Murthy, V., Kanan, S., Shetty, R., Nair, M., \& Khattry, N. (2016). Introduction of situation, background, assessment, recommendation into nurse practice: A prospective study. Asia-Pacific Journal of Oncology Nursing, 3:1, 4550.

Anderson, C.D., \& Mangino, R.R. (2006). R.R. Nurse shift report who says you can’t talk in front of the patient? Nurse Administration Quarterly, 7:48, 112-122.

Cairns, L.L., Dudjak, L.A., Hoffmann, R.L., \& Lorenz, H.L. (2013). Utilizing bedside shift report to improve the effectiveness of shift handoff. The Journal of Nursing Administraiotn,43:3, 160-165.

Cornell, P., Gervis, M. T., Yates, L., \& Vardaman, J.M. (2014). Impact of SBAR on nurse shift reports and staff rounding. MedSurg Nursing, 23:5, 334-342.

Dufault, M. (2017, September 7). Translating an evidence-based protocol for nursing shift handoffs: feasibility, cost, and 10-year sustainability outcomes. Presented at the 2017 World Congress on Nursing Research and Education. Retrieved February 8, 2018.

Dufault, M., Duquette, C., Willey, C., Ehmann, J., Gordon, D.M., Lavin, M., et al. (2013). Translating an evidence-based protocol for nurse-to-nurse shift handoffs. Abstract retrieved February 8, 2018.

Dufault, M., Duquette, C., Ehmann, J., Hehl, R., Lavin, M., Martin, V., Moore, M., et al. (2010). Translating an evidence-based protocol for nurse-to-nurse shift handoffs. Worldviews on Evidence-Based Nursing, Second Quarter, 59-75. 
Duquette, C., Willey, C., Christopher, J., DelaCruz, J., Ducharme, M., Dunbar, J., et al. (2013, October). Outcomes of a RCT on translating an evidence-based protocol for nurses shift handoffs. Presented at the 2013 ANCC International Magnet Research Conference. Retrieved February 8, 2018.

Evans, D., Granawalt, J., McClish, D., Wood, W., \& Frieses, C. R. (2012). Bedside shift-to-shift nursing report: Implementation and outcomes. Medsurg Nursing, 21:5, 281-292.

Fryman, C., Hamo, C., Raghavan, S., \& Goolsarran, N. (2017). A quality improvement approach to standardization a sustainability of the hand off process. MBJ Quality Improvement Reports, 6, 1-6.

Johnson, C., Carta, T., \& Throndson, K. (2015). Communicate with me: Information exchanges between nurses. Canadian Nurse, 3:2, 24-27.

Kaiser Permanente (March 1 2007). Shifting perspectives. Kaiser Permanente. Retrieved from https://share.kaiserpermanente.org/article/shifting-perspectives/

Kaufman, J. (2008) Patients as partners. Nursing Management, 39, 45-48.

Kear, T. M. (2016). Patient handoffs: What they are and how they contribute to patient safety. Nephrology Nursing Journal, 43:4, 339-342.

Kohn, L.T., Corrigan, J. M., \& Donaldson, M.S. (Eds.). (2000). To err is human: Building a safer health system. Washington, D.C.: National Academy Press.

Maxson, P. M., Derby, K. M., Wrobleski, D. M., \& Foss, D. M. (2012). Bedside nurseto-nurse handoff promotes patient safety. Medsurg Nursing, 21:3, 140-144. 
Nasarwanji. M.F., Nador, A., \& Gurses, A.P. (2016). Standardizing handoff communication: Content analysis of 27 handoff mnemonics. Journal of Nursing Care Quality, 31:3, 238-244.

Rogers, E.M. (2003). Diffusion of innovations. New York, New York: Free Press.

Sherman, J., Sand-Jecklin, K., \& Johnson, J. (2013). Investigating bedside report: a synthesis of the literature. MedSurg Nursing, 22:5, 308-318.

Sand-Jecklin, K., \& Sherman, J. (2014). A quantitative assessment of patient and nurse outcomes of bedside report implementation. Journal of Clinical Nursing, 23, 2854-2863.

Taylor, J.S. (2015). Improving patient safety and satisfaction with standardized bedside handoff and walking rounds. Clinical Journal of Oncology Nursing, 16:4, 414416.

The Joint Commission. (2007). Improving America's hospitals: The joint commission's annual report on quality and safety (sentinel event root cause and trend data). Retrieved from https://www.jointcommission.org/assets/1/6/2007_Annual_Report.pdf

The Joint Commission. (2016). Critical access hospital: 2017 national patient safety goals. Retrieved from https://www.jointcommission.org/assets/1/6/2017_NPSG_HAP_ER.pdf

The Joint Commission Center for Transforming Healthcare. (2014). Improving transitions of care: Hand-off communications. Retrieved from http://www.centerfortransforminghealthcare.org/assets/4/6/handoff_comm_storyb oard.pdf 
Timonen, L. \& Sihvonen, M. (2000). Patient participation in bedside reporting on surgical wards. Journal of Clinical Nursing, 9, 542-548.

Tobiano, G., Chaboyer, W., \& McMurray, A. (2012). Family members' perception of the nursing bedside handover. Journal of Clinical Nursing, 22, 192-200.

Welsh, C.A. Flanagan, M.E. \& Ebright, P. (2010). Barriers and facilitators to nursing handoffs: Recommendations for redesign. Nursing Outlook, 58:3, 148-154. 


\section{Appendix A}

SBARP (Situation, Background, Assessment, Recommendation and Patient) Nurse to Nurse Handoff at the Bedside

Number of years as an $\mathrm{RN}$ (please circle one)

$1-5 \quad 6-10 \quad 11+$ years

What percentage of time do you perform nurse to nurse patient handoff at the patient's bedside (please circle one)

$\begin{array}{lllll}0 \% & 1-25 \% & 26-50 \% & 51-75 \% & 76-99 \%\end{array}$ $100 \%$

If you do not perform handoff at the bedside $100 \%$ of the time, where do you give report (please circle one)?

Outside of the patient's room

Nurse's station

Break room

Other (Please specify):

\section{Please Rate the following statements on a scale of 1-5. Circle your choice}
1: Strongly Disagree
2: Disagree
3: Neutral
4. Agree
5: Strongly Agree
Bedside report decreases the length of time I spend in report.
$\begin{array}{lllll}1 & 2 & 3 & 4 & 5\end{array}$ 
Patients do not mind being interrupted for bedside report.

$\begin{array}{lllll}1 & 2 & 3 & 4 & 5\end{array}$

Bedside report in a double occupancy room does not violate a patient's privacy.

$\begin{array}{lllll}1 & 2 & 3 & 4 & 5\end{array}$

In general, patients interact appropriately during bedside report. $\quad \begin{array}{lllllll}1 & 2 & 3 & 4 & 5\end{array}$

Sensitive test results should not be discussed during bedside report. $\begin{array}{lllllll}1 & 2 & 3 & 4 & 5\end{array}$

$\begin{array}{llllll}\text { Bedside report helps prevent patient safety problems. } & 1 & 2 & 3 & 4 & 5\end{array}$

$\begin{array}{llllll}\text { Patient requests cause bedside report to take longer. } & 1 & 2 & 3 & 4 & 5\end{array}$

Including the patient in bedside report increases patient satisfaction. $\begin{array}{lllll}1 & 2 & 3 & 4 & 5\end{array}$

Bedside report in a double occupancy room violates a patient's privacy. $\begin{array}{lllll}1 & 2 & 3 & 4 & 5\end{array}$

$\begin{array}{llllll}\text { Any test results can be discussed during beside report. } & 1 & 2 & 3 & 4 & 5\end{array}$

Patients do not want to be interrupted for bedside report. $\quad \begin{array}{lllll}2 & 3 & 4 & 5\end{array}$

$\begin{array}{llllll}\text { Bedside report increases patient involvement in care. } & 1 & 2 & 3 & 4 & 5\end{array}$

$\begin{array}{llllll}\text { Bedside report does not impact patient safety. } & 1 & 2 & 3 & 4 & 5\end{array}$

Patients satisfaction is not impacted by bedside report. $\quad \begin{array}{lllll}2 & 3 & 4 & 5\end{array}$

Please identify why you perform full SBARP report at the patient's bedside:

Please list some barriers to performing SBARP report at the patient's bedside: 


\section{Appendix B}

Proof of Approval by Orla Brandos (CNO of Newport Hospital), Kathy Bergeron (manger of education at Newport Hospital), Sarah Nekrasz (Clinical Manager of Tuner 2), and Lindsey Rhodes (Clinical Manager of Turner 4)

From: Brandos, Orla M

Sent: Friday, July 21, 2017 2:24 PM

To: Bryand, Elizabeth

Cc: Nekrasz, Sarah A; Rhodes, Lindsey E

Subject: RE: RIC MSN Project

Hi Liz, Welcome to Newport, looking forward to meeting you. Hope you are settling in ok.

Congratulations on continuing to pursue your education, sounds like a great project. I support you surveying the nurses on T2 and T4 however I would like Sarah Nekrasz, Nurse Manager of T2 and Lindsey Rhodes, Nurse Manager of T4 approve this request also. We survey nurses on many different topics and I just want to make sure that Lindsey and Sarah are ok with it first.

Please let me know if there is anything else I can be of assistance with.

Have a great weekend,

Orla

Orla Brandos, DNP, MBA, MSN, RN, CPHQ, NEA-BC

Vice President of Patient Care Services / Chief Nursing Officer

Newport Hospital

11 Friendship Street

Newport, RI 02840

Phone: 401-845-1530

Bergeron, Kathleen t

\section{Reply all}

Fri 7/21/2017, 1:23 PM

Bryand, Elizabeth;

Brandos, Orla M

Hello,

Just to add my voice to Liz's request- Liz and I discussed her project and the potential value to Newport Hospital. Staff participation in this survey will be anonymous and voluntary. Liz will also apply to the TMH and RIC IRBs for her project.

Thank you, 
Kathy

From: Nekrasz, Sarah A

Sent: Monday, July 24, 2017 9:21 AM

To: Brandos, Orla M; Bryand, Elizabeth

Cc: Rhodes, Lindsey E

Subject: RE: RIC MSN Project

I have no issues with this. It sounds great.

From: Rhodes, Lindsey E

Sent: Monday, July 24, 2017 12:40 PM

To: Nekrasz, Sarah A <SNekrasz@Lifespan.org>; Brandos, Orla $\mathrm{M}<\underline{\text { Orla.Brandos@Lifespan.org>; }}$

Bryand, Elizabeth<Ebryand1@Lifespan.org>

Subject: RE: RIC MSN Project

Sorry, Just catching up on emails. That sounds fine for T4 as well, sounds like an interesting and timely topic.

Lindsey Rhodes 


\section{Appendix C}

\section{Staff Notification Email}

Hello,

Kathy Bergeron is the principal investigator and mentor for this project. As part of a graduate research project, Elizabeth Bryand, Clinical Nurse Specialist student at Rhode Island College, and Kathy Bergeron, nurse educators at Newport Hospital, are distributing a survey to identify nurses' perceived beliefs of performing SBARP (Situation, Background, Assessment, Recommendation and Patient) at the bedside. The survey is now available, and located in the break room. If you are interested in participating in this research study, please review the informational letter attached to the survey. If you then decide to participate, complete the survey and place it in the sealed box provided. Responses are anonymous and your decision to participate or not is your choice. The unit with the highest participation will receive a basket of candy. 


\section{Appendix D}

\section{Script for Staff Huddle Announcements}

Kathy Bergeron is the principal investigator and mentor for this project.As part of a graduate research project, Elizabeth Bryand, Clinical Nurse Specialist student at Rhode Island College, and Kathy Bergeron, nurse educators at Newport Hospital, are distributing a survey to identify nurses' perceived beliefs of performing SBARP (Situation, Background, Assessment, Recommendation and Patient) at the bedside. The survey is now available, and located in the break room. If you are interested in participating in this research study, please review the informational letter attached to the survey. If you then decide to participate, complete the survey and place it in the sealed box provided. Responses are anonymous and your decision to participate or not is your choice. The unit with the highest participation will receive a basket of candy. 


\section{Appendix E}

Informational Letter

To All Turner 2, Turner 4 and Float Staff Nurses

My name is Elizabeth Bryand, a Clinical Nurse Specialist (CNS) student at Rhode Island College. I am performing this research projects as part of the MSN program requirements. Kathy Bergeron, is the primary investigator of this research. You are invited to participate in a research study by completing a survey addressing SBARP report at the patient bedside. All Registered Nurses at Newport Hospital who are staff nurses on Turner 2, Turner 4 or who float to provide patient care on Turner 2 or Turner 4 are invited to complete the survey. The purpose of this research is to identify nurses' perceived beliefs of performing SBARP at the bedside in an acute care setting.

The survey will be available for two weeks. Participation in this survey will be anonymous.

The survey will not include any identifying information. Completed surveys maybe submitted in the sealed box located in the staff breakroom. Completed survey will be collected by the researcher and stored in a secure location.

The survey should take 10 minutes or less and involves no identifiable risks. There will be no direct benefits to participants. If you are uncomfortable with a question please feel free to leave the question blank. Responses will be anonymous.

If you have any questions or concerns please contact me at ebryand_3809@email.ric.edu or call me at 401-486-2010, or Kathy Bergeron at kbergeron@lifespan.org. If you have 
any questions about your rights as a participant you may also contact the Janice Muratori, the Lifespan Institutional Review Board director, at 401-444-6897. You may also contact Patti Calvert, major advisor of this project at pcalvert@,ric.edu or the Rhode Island College IRB chair at $\underline{\text { irb@ric.edu. }}$

Thank you for your participation,

Elizabeth Bryand, RN 


\section{Appendix F}

\section{Data Collection Grid}

\begin{tabular}{|c|c|c|c|c|c|}
\hline & Number of Years as RN & $1-5$ & $6-10$ & $10+$ & All \\
\hline $\begin{array}{c}\text { Number } \\
\text { of }\end{array}$ & $\begin{array}{c}\text { Bedside Report Percentage - } \\
0 \%\end{array}$ & 2 & 0 & 0 & 2 \\
\hline \multirow[t]{5}{*}{ Responses } & $\begin{array}{c}\text { Bedside Report Percentage } \\
\qquad 1-25 \%\end{array}$ & 5 & 3 & 3 & 11 \\
\hline & $\begin{array}{c}\text { Bedside Report Percentage } \\
26-50 \%\end{array}$ & 1 & 0 & 0 & 1 \\
\hline & $\begin{array}{c}\text { Bedside Report Percentage } \\
\qquad 51-75 \%\end{array}$ & 0 & 0 & 1 & 1 \\
\hline & $\begin{array}{c}\text { Bedside Report Percentage } \\
76-99 \%\end{array}$ & 1 & 1 & 1 & 3 \\
\hline & $\begin{array}{c}\text { Bedside Report Percentage } \\
100 \%\end{array}$ & 0 & 0 & 1 & 1 \\
\hline Number & Outside of the patient's room & 2 & 3 & 1 & 6 \\
\hline of & Nurse's Station & 7 & 3 & 5 & 15 \\
\hline Response: & Break Room & 0 & 0 & 0 & 0 \\
\hline $\begin{array}{l}\text { Location } \\
\text { of Report }\end{array}$ & Other (Please Specify) & 0 & 0 & 0 & 0 \\
\hline
\end{tabular}




\begin{tabular}{|c|c|c|c|c|c|}
\hline \multirow[t]{8}{*}{$\begin{array}{l}\text { Average } \\
\text { Score }\end{array}$} & $\begin{array}{c}\text { Bedside report decreases the } \\
\text { length of time I spend in } \\
\text { report }\end{array}$ & 2.5 & 3 & 2.67 & 2.72 \\
\hline & $\begin{array}{l}\text { Patients do not mind being } \\
\text { interrupted for bedside report }\end{array}$ & 3.13 & 3 & 2.17 & 2.72 \\
\hline & $\begin{array}{l}\text { Bedside report in a double } \\
\text { occupancy room does not } \\
\text { violate a patient's privacy }\end{array}$ & $2.44 / 3.55$ & $1 / 5$ & $1 / 5$ & $1.68 / 4.32$ \\
\hline & $\begin{array}{l}\text { In general patients interact } \\
\text { appropriately during bedside } \\
\text { report }\end{array}$ & 3.63 & 3.5 & 3 & 3.56 \\
\hline & $\begin{array}{l}\text { Sensitive test results should } \\
\text { not be discussed during } \\
\text { beside report }\end{array}$ & 3.44 & 5 & 4.5 & 4.11 \\
\hline & $\begin{array}{c}\text { Bedside report helps prevent } \\
\text { patient safety problems }\end{array}$ & 3.77 & 3.75 & 4.17 & 4.16 \\
\hline & $\begin{array}{l}\text { Patient requests cause } \\
\text { bedside report to take longer }\end{array}$ & $4.33 / 1.66$ & $3.75 / 2.25$ & $2.67 / 1.83$ & $3.42 / 1.84$ \\
\hline & $\begin{array}{l}\text { Including the patient in } \\
\text { bedside report increases } \\
\text { patient satisfaction }\end{array}$ & 3.56 & 3.5 & 3.33 & 3.47 \\
\hline
\end{tabular}




\begin{tabular}{|c|c|c|c|c|}
\hline $\begin{array}{c}\text { Bedside report in double } \\
\text { occupancy rooms violates a } \\
\text { patient's privacy }\end{array}$ & 4.33 & 5 & 5 & 4.68 \\
\hline $\begin{array}{l}\text { Any test result can be } \\
\text { discussed during bedside } \\
\text { report }\end{array}$ & $2.11 / 3.88$ & $1.25 / 4.75$ & $1.5 / 4.5$ & $1.63 / 4.26$ \\
\hline $\begin{array}{l}\text { Patients do not want to be } \\
\text { interrupted for bedside report }\end{array}$ & $2.89 / 3.11$ & $2.25 / 3.75$ & $3.17 / 2.83$ & $2.84 / 2.58$ \\
\hline $\begin{array}{c}\text { Bedside report increases } \\
\text { patient involvement in care }\end{array}$ & 4.22 & 4.5 & 4 & 4.16 \\
\hline $\begin{array}{l}\text { Bedside report does not } \\
\text { impact patient safety }\end{array}$ & $2.5 / 3$ & $2 / 4$ & $1.83 / 4.17$ & $2.37 / 3.54$ \\
\hline $\begin{array}{l}\text { Patients' satisfaction is not } \\
\text { impacted by bedside report }\end{array}$ & $2.44 / 2.56$ & $1.75 / 4.25$ & $2.33 / 3.67$ & $2.26 / 3.74$ \\
\hline
\end{tabular}

*Average scores listed after “/” were calculated with reverse scoring for negative questions 


\section{Appendix G}

Qualitative Responses Classified as Positive, Negative or Mixed Feelings Toward

Bedside Handoff

\begin{tabular}{|c|c|c|}
\hline Positive & Mixed & Negative \\
\hline $\begin{array}{l}\text { To make sure patient is okay, } \\
\text { if they need anything they are } \\
\text { in pain, so that they know } \\
\text { what is going on }\end{array}$ & $\begin{array}{l}\text { I try to combine the } \\
\text { approach. Do a quick } \\
\text { report at the nurse's } \\
\text { station with computer } \\
\text { then go into room and } \\
\text { answer quick questions } \\
\text { and make sure the patient } \\
\text { is ok }\end{array}$ & $\begin{array}{l}\text { I prefer report at nurses' station } \\
\text { where details can be reviewed } \\
\text { thoroughly }\end{array}$ \\
\hline $\begin{array}{l}\text { Give patient the opportunity } \\
\text { to ask questions and clarify } \\
\text { info during RN handoff }\end{array}$ & & Because we were told we have to \\
\hline Decrease time giving report & & $\begin{array}{l}\text { MDs don't even tell patient's } \\
\text { families what's going on and why. } \\
\text { Puts RN on spot when family asks } \\
\text { questions before reading chart }\end{array}$ \\
\hline $\begin{array}{l}\text { To give next RN a complete } \\
\text { report including the patient } \\
\text { helps keep them updated on } \\
\text { current plan of care and tests }\end{array}$ & & Because that is the new protocol \\
\hline $\begin{array}{l}\text { Include patient, look at safety } \\
\text { stuff, handoff }\end{array}$ & & \\
\hline $\begin{array}{l}\text { Monitor correct fluids } \\
\text { infusing }\end{array}$ & & \\
\hline $\begin{array}{l}\text { To keep patient's informed, } \\
\text { check dressings, IVF, tubing } \\
\text { labels, high risk med } \\
\text { infusions (PCAs), to check } \\
\text { bed alarms, safety measures, } \\
\text { decrease time/questions } \\
\text { compared to if done at } \\
\text { nursing station, decrease call } \\
\text { bells at change of shift }\end{array}$ & & \\
\hline \multicolumn{3}{|l|}{$\begin{array}{l}\text { Prevent falls, include the } \\
\text { patient in the plan of care }\end{array}$} \\
\hline $\begin{array}{l}\text { Continuity of care, patient } \\
\text { safety, decreases patient } \\
\text { anxiety }\end{array}$ & & \\
\hline
\end{tabular}


